\title{
Personalidade Civil: no Direito Romano e no Direito Atual
}

Andréia Sabóia Medeiros

Estudante de Direito da

Faculdade 7 de Setembro 



\section{Personalidade Civil: no Direito Romano e no Direito Atual}

\section{CO INTRODUÇÃO}

A personalidade jurídica, a susceptibilidade de direitos e obrigações, corresponde a uma condição indispensável da realização por cada homem dos seus fins ou interesses na vida com os outros - e o direito existe a serviço dos homens. Hoje, o reconhecimento dessa qualidade jurídica a todos os seres humanos não é mais motivo de discussões.

O estudo a seguir conceituará personalidade, analisando-a frente ao Direito Romano e, posteriormente, no Direito atual, onde perceberemos quão importantes e numerosas foram as contribuições do Direito Romano para nosso direito moderno.

\section{co Personalidade no Direito Romano}

\subsection{Pessoa Física ou Natural}

O sujeito de direito é denominado, tecnicamente, no direito moderno, pessoa ${ }^{1}$. Os romanos não possuíam termo específico para denominar pessoa. A palavra persona, donde veio pessoa, inicialmente significou máscara, posteriormente personagens, por fim, como estes são criaturas humanas, persona ganhou maior extensão, vindo a significar o próprio homem $^{2}$. E baseado em passagem única das Institutas ${ }^{3}$, preleciona AGERSON TABOSA: "Embora os romanos não a tenham empregado com essa significação precisa, persona, designou o homem capaz de direitos" ${ }^{4}$.

\footnotetext{
${ }^{1}$ José Carlos Moreira Alves, Direito Romano, p. 90.

Agerson Tabosa, Direito Romano, p.127.

3 Institutas, 1, 16, 4: "Servus nullum caput habet”--O escravo não tem nenhuma capacidade.

${ }^{4}$ Agerson Tabosa, op cit, p.128.
} 
Existem duas categorias de pessoas: as pessoas físicas ou naturais (homens e mulheres que não fossem os escravos) e as pessoas jurídicas ou morais.

\section{2. REQUISITOS}

As pessoas físicas são os seres humanos, mas, nem todo ser humano é pessoa física (basta verificar a condição do escravo) ${ }^{5}$. Para ser considerado pessoa física era mister o preenchimento de alguns requisitos, uns que se relacionam com a existência e outros com a capacidade. Nesse ponto, verificamos que o Direito Romano era mais criterioso que o direito brasileiro, como analisaremos a seguir.

\section{2. 1. Requisitos de Existência}

Modernamente, basta o nascimento com vida para que se configure, juridicamente, o ser humano ${ }^{6}$. No entanto, em Roma, os requisitos para o reconhecimento existencial da pessoa se verificava quando eram preenchidas três condições: nascer vivo, ter forma humana e ser viável.

Nascer vivo - Segundo os juristas romanos, o feto era apenas porção da mulher ou de suas víceras "partus enim antequam edatur, mulieris portio est uel uiscerum" 7 = o feto antes de vir à luz é porção da mulher, ou de suas víceras, portanto, não podia ser considerado homem "partus nondum editus homo nos recte fuisse dicitur" = o feto que ainda não foi dado à luz não se diz que seja um homem ${ }^{8}$. Verifica-se, com clareza, que era preciso não só o nascimento, mas sim, que ocorresse também a vida extra-uterina. O nascituro, por não preencher ainda esse primeiro requisito, não é considerado ser humano, mas, desde a concepção é protegido. E para resguardar o direito do nascituro, a mulher que o está gerando pode requerer ao magistrado competente a nomeação de um curador, que terá como objetivo resguardar direitos que ele virá a ter quando for considerado pessoa física.

Ter forma humana-O nascimento não bastava, era preciso que o recém nascido tivesse forma humana ${ }^{9}$. Uma particularidade do direito romano não acolhida pelo direito brasileiro. No Código espanhol (art. 30) perma-

\footnotetext{
${ }^{5}$ José Carlos Moreira Alves, op cit, p.90

${ }^{6} \mathrm{CCB}$, art.2 "A personalidade começa com o nascimento com vida...”

${ }^{7}$ Digesto, 25, 4, 1, 1, Ulpiano

${ }^{8}$ Digesto, 35, 2, 9, 1, Papiniano

${ }^{9}$ Digesto, 1, 5, 14, Paulo: “Non sunt liberi qui contra formam humani generis more procreantur".
} 
nece ainda essa exigência no recém-nascido e que tenha vivido desprendido do seio materno por 24 horas $^{10}$. O indivíduo considerado monstrum jamais podia ter personalidade, capacidade jurídica. Segundo os romanos, existia essa hipótese que caracterizava como monstro o ser nascido de mulher: se, no todo ou em parte, possuísse configuração de animal (os romanos acreditavam na possibilidade da cópula entre mulher e animal que resultaria em seres híbridos). Hoje, via de regra, percebeu a medicina total impossibilidade do nascimento de novos seres em virtude desse tipo de relação carnal.

Ser viável-Além do nascimento com vida e da forma humana era preciso que o recém-nascido apresentasse a possibilidade de viver, aptidão à vida, sendo esta mais um requisito para à existência da pessoa física. Ao nascido prematuramente, antes de um período mínimo de seis meses, não era atribuída a personalidade, porquanto, segundo Hipócrates, esse era o menor tempo de gestação necessária para que a criança, depois de nascida, continuasse à viver, antes disso era considerado aborto.

\section{2. 2. Requisitos de Capacidade}

O Direito Romano não reconhecia a todo e qualquer homem a qualidade de ser sujeito de direitos, como veremos no Direito Brasileiro, o escravo não possuía essa qualidade, uma vez que era considerado coisa (res ), portanto, era considerado objeto de direitos. Além dos requisitos de existência já vistos acima, é necessário ter capacidade jurídica, ter personalidade. Primeiramente, é necessário fazer a diferença entre capacidade de direito e capacidade de fato. Capacidade de direito é a aptidão para a titularidade, inerente a toda pessoa física, e a capacidade de fato é a aptidão para o exercício ${ }^{11}$. Por exemplo, em Roma, um impúbere sui júris tinha capacidade de direito, mas não possuía capacidade de fato uma vez que não podia produzir os efeitos decorrentes dos seus direitos.

No Direito Romano existiam os requisitos que serviam para avaliar a capacidade jurídica das pessoas, limitando aqueles que a tinham completamente. Esses requisitos eram chamados de status, que eram em número de três: status libertatis, status civitatis e status familiae.

${ }^{10} \mathrm{CCE}$, "Para los efectos civiles, solo se reputará nascido el feto que tuviere figura humana y viviere veinticuatro horas enteramente desprendido Del seno materno”.

${ }^{11}$ Agerson Tabosa, op cit, p. 132. 
O Status Libertatis informava qual a posição do indivíduo perante a liberdade. No direito romano, ou os homens são livres ou são escravos ${ }^{12}$. Os livres, por possuírem liberdade, tinham capacidade jurídica. Os escravos, por não serem livres, não podiam ser pessoas, logo, não tinham nenhuma capacidade. Por exemplo, não podiam casar-se legitimamente, não tinham patrimônio, não podia ser parte em juízo, enfim, eram apenas objetos de direito subjetivo. No Status Civitatis as pessoas, perante a cidade, podiam ser cives (cidadãos) ou peregrini (estrangeiros). Os estrangeiros sempre possuíram capacidade reduzida em relação aos cidadãos, estes podiam ter a capacidade plena. O cidadão romano possuía a faculdade de eleger-se magistrado (ius honorum), direito de votar (ius suffragii), dentre outros que não eram concedidos aos estrangeiros. Por fim, no Status Familiae, as pessoas, dentro da família romana, ou eram sui júris, ou seja, independentes do pátrio poder, com plena capacidade, ou eram alieni júris, isto é, de direito alheio, dependentes do pátrio poder, portanto, com capacidade reduzida. Esse status determina qual a amplitude da capacidade jurídica do cidadão no campo do direito.

Concluímos que para que o ser humano, no Direito Romano, adquirisse personalidade jurídica eram necessárias três características: ser livre, ser cidadão romano e que fosse sui júris.

\section{2. 3. Cápitis Deminutiones}

A capacidade da pessoa física não era permanente, imutável. Por existirem os status, a capacidade da pessoa podia sofrer alterações que geralmente resultavam em reduções. Em virtude disso, a denominação de cápitis deminutiones, ou seja, diminuição de capacidade. Dependendo da intensidade da redução produzida, a cápitis deminutio podia ser máxima, média e mínima ${ }^{13}$.

Máxima - A pessoa que porventura perdesse a liberdade, sofria a máxima diminuição. Perderia a condição de pessoa, persona, e passava a ser escravo. Perdia o status libertatis, portanto, tornava-se inábil para ser titular de qualquer direito, era a sua própria morte civil, retirava do indivíduo o requisito da capacidade.

\footnotetext{
${ }^{12}$ Institutas, 1, 3, pr.: "Summa itaque divisio de jure personarum haec est, quod omnes aut líberi sunt aut servi”.

${ }^{13}$ Institutas, 1, 16, pr.
} 
Média - sofria a cápitis deminutio média o romano que perdesse a cidadania, passando a ser estrangeiro, e, em conseqüência, sofria restrições de direito inerentes aos estrangeiros. Essas restrições podiam abranger a esfera pública ou privada.

Mínima - A mudança de um indivíduo que era sui júris e passa a ser alieni júris implica em uma diminuição de capacidade que os romanos consideravam mínima. Era a cápitis deminutio mínima.

Além desses fatores que citamos acima, poderiam existir outras alterações que afetariam a capacidade das pessoas. Os principais fatores estavam ligados à idade, a saúde, sexo e religião.

Frente ao exposto, finalizamos o estudo sobre a personalidade no Direito Romano. Adiante, analisaremos a personalidade no Direito Brasileiro.

\section{Personalidade no Direito Brasileiro}

\subsection{Conceito}

Personalidade é o conjunto de princípios e de regras que protegem a pessoa, o ser humano, em todos os seus aspectos e manifestações.

A personalidade está intimamente ligada à idéia de pessoa, pois exprime a aptidão genérica para adquirir direitos e contrair obrigações ${ }^{14}$. Hoje, como resultado de uma conquista jurídica, ela é reconhecida a todo ser humano. ORLANDO GOMES, vale ressaltar, enfatizou ser a personalidade um atributo jurídico. Personalidade jurídica érequisito indispensável para ser sujeito de direito. A personalidade não irá depender da consciência e, muito menos, da vontade do indivíduo. O recém-nascido, o deficiente mental ou mesmo o indivíduo portador de enfermidade que por estas razões não podem exprimir consciência ou vontade são pessoas, logo, possuem personalidade.

Uma vez adquirida a personalidade o indivíduo, na qualidade de sujeito de direito (pessoa natural ou pessoa jurídica), passa a praticar os atos e negócios jurídicos dos mais diferentes modos. Considerada como sujeito de direito, a personalidade não pode ser dele seu objeto ${ }^{15}$ não se excluindo na categoria de direito subjetivo; neste caso, os chamados

${ }^{14}$ Clóvis Bevilaqua, Teoria Geral, § $3^{\circ}$.

${ }^{15}$ Gustavo Tepedino, Temas de Direito Civil, p. 27. 
direitos da personalidade, expressamente reconhecidos pelo novo Código Civil (artigos 11 a 21) que buscam a visão da pessoa como valor, reconhecendo os atributos inerentes e indispensáveis a todo e qualquer ser humano. A personalidade, portanto, é o instituto básico do direito civil, e a pessoa, o seu núcleo fundamental. O direito protege-a e garante-lhe a reprodução e a conservação, por meio dos direitos da personalidade, do direito de família e do direito patrimonial.

No que se refere à pessoa natural ou física, objeto do Capítulo I, do Novo Código Civil, que substituiu a expressão “homem” por “pessoa”, excluindo qualquer tipo de discriminação, dispõe em seu art. $1^{\circ}$, que: "Art. $1^{\circ}$ Toda pessoa é capaz de direitos e deveres na ordem civil”. Concluiu-se que a personalidade é atributo de qualquer pessoa, com um sentido de universalidade, como o artigo supracitado menciona, seja ela pessoa natural ou jurídica ${ }^{16}$.

\subsection{Aquisição da personalidade}

A personalidade está intimamente ligada à pessoa humana. Sua duração, portanto, é a vida. Desde que o homem vive e enquanto viver possuirá personalidade. Afirmar que o homem tem personalidade é o mesmo que dizer que ele tem capacidade para ser titular de direitos ${ }^{17}$.

A personalidade jurídica, em nosso direito, tem início no nascimento com vida. Existem dois requisitos únicos: o nascimento e vida. O natimorto não adquire personalidade.

Entende-se por nascimento quando o feto é separado do ventre materno, naturalmente ou utilizando qualquer recurso obstétrico. A unidade biológica é desfeita, mãe e filho constituem dois corpos com manutenção orgânica própria.

A vida de um novo ser configura-se no momento em que se opera a primeira troca oxicarbônica no meio ambiente. Viveu a criança que tiver inalado ar atmosférico, ainda que deixe de existir em seguida. Desde que tenha respirado, viveu: a entrada de ar nos pulmões denota a vida, mesmo que não tenha sido cortado o cordão umbilical ${ }^{18}$. A prova poderá

${ }^{16}$ Silvio Rodrigues, Direito Civil, vol. I, p.35, n.16.

${ }^{17}$ Caio Mário da Silva Pereira, a propósito, anotou: "Em o direito brasileiro, a idéia da concessão de personalidade a todo ser humano vigorou mesmo ao tempo da escravidão negra, muito embora o regime jurídico do escravo não o equiparasse ao homem livre”. ( Instituições de Direito Civil, vol I, p.142, n.42).

${ }^{18}$ De Page, Traité Elementaire , I, n ${ }^{\circ} 236$. 
ser feita utilizando todos os meios e os processos técnicos que a medicina legal proporcione para verificação da entrada de ar nos pulmões. Exame bastante utilizado e tido como o principal, é a docimasia hidrostática de Galeno $^{19}$. A partir desse momento, se inicia a personalidade civil.

A partir do nascimento com vida é que integram os direitos e as obrigações e passa a existir a pessoa. Até o nascimento, o que existem são direitos potenciais, que para se constituírem de fato, precisam aguardar o nascimento e a aquisição da personalidade. Se nascer vivo, ainda que pereça em seguida, o novo ser chegou a ser pessoa, adquiriu direitos e, com sua morte, conseqüentemente os transmite. Os requisitos (nascimento e vida) que são necessários para a aquisição da personalidade mostram seu caráter prático quando se passa para a matéria sucessória, uma vez que, mesmo vivendo por alguns segundos, o recém-nascido recebe, adquire e transmite direitos aos seus sucessores.

\subsection{O Nascituro}

O nascituro é o ser já concebido, mas que se encontra no ventre materno ${ }^{20}$. O artigo $2^{\circ}$ do novo Código Civil brasileiro contempla, assim como na codificação de 1916, que a personalidade se inicia com o nascimento com vida e a lei protege, desde a concepção, os direitos do nascituro. E este acontecimento (nascimento com vida) é que torna possível a aquisição e a perda de direitos subjetivos pelo indivíduo. E, embora o nascituro não seja considerado pessoa, ele possui a proteção legal dos seus direitos desde a concepção. Assim, é obrigatória a nomeação de um curador, se o pai falecer estando grávida a mulher, e não tendo esta o poder familiar (art. 1779); pode o nascituro ser objeto de reconhecimento voluntário de filiação (art. 1.609, parágrafo único); pode receber doação (art. 542) e ser contemplado em testamento (art. 1.798); tem direito a uma adequada assistência pré-natal (ECA, art. $8^{\circ}$ ). O Direito Penal também o protege, penalizando o aborto. E a Constituição Federal assegura a todos, sem distinção, o direito à vida $\left(\text { art. } 5^{\circ}\right)^{21}$. Preleciona, a propósito, Carlos Alberto Bittar:

${ }^{19}$ Esse exame é baseado na diferença de peso específico entre o pulmão que respirou e o que não respirou, mergulhados na água, como nos informa Sérgio Abdalla Semião. (Os Direitos do Nascituro-Aspectos Cíveis, Criminais e do Biodireito, Belo Horizonte, Del Rey, 1998, p. 158-9.

20 Silvio Rodrigues, Direito civil,vol I, p. 36.

${ }^{21}$ Carlos Roberto Gonçalves, Direito Civil Brasileiro, vol. I, p.80. 
"Adotou-se o sistema em que se tem como o início da personalidade o nascimento com vida, mas se respeitam o direito do nascituro, desde a concepção, ou seja, quando formado o novo ser. Conforme esse entendimento, ficam sob condição da vinda à lume os direitos do nascituro, considerando-se como tal a exalação do primeiro sopro de vida após a separação da mãe, que demonstra afirmação da nova existência, diversa da genitora, cabendo daí, pois, ao filho todos os direitos reconhecidos à pessoa humana no plano jurídico. Mesmo que venha a falecer em seguida consideram-se adquiridos os direitos, para todos os efeitos próprios, protegendo-se assim os interesses do nascituro e do respectivo círculo familiar"22.

Importante salientar que o natimorto não adquire personalidade, pois se entende que alguém nasceu com vida quando respira ao ser separado da mãe ${ }^{23}$. Várias teorias surgiram na doutrina com o objetivo de esclarecer qual o momento que se iniciava a personalidade. A teoria concepcionista, influenciada pelo Direito francês, afirmava que o nascituro adquiria personalidade jurídica desde a concepção e, portanto, considerado pessoa. Essa teoria foi seguida por Limongi França, Francisco Amaral dos Santos e Teixeira de Freitas. A teoria da personalidade condicional concluiu que o nascituro possui direitos em condição suspensiva. Nessa linha, ensina Arnold Wald: “A proteção do nascituro explica-se, pois há nele uma personalidade condicional que surge, na sua plenitude, com o nascimento com vida e se extingue no caso de não chegar o feto a viver ${ }^{24}$. É a posição de Oertmann e Miguel Maria de Serpa Lopes. E finalmente, a teoria natalista, que afirma não ser o nascituro pessoa, pois possui apenas expectativas de direitos e que o início da personalidade se opera a partir do nascimento com vida.

Considerando a maior parte da doutrina, segue-se o raciocínio da teoria natalista em que o nascituro possui mera expectativa de direitos e, por não ser considerado pessoa, esses direitos se apresentam em estado potencial.

\footnotetext{
${ }^{22}$ Carlos Alberto Bittar, Curso de Direito Civil, vol. I, p.79.

${ }^{23}$ Orlando Gomes, Introdução ao Direito Civil, p. 144.

${ }^{24}$ Arnold Wald, Curso de Direito Civil Brasileiro- Introdução e Parte Geral, p. 120.
} 


\section{4. Fim da Personalidade}

Como a existência da pessoa natural termina com a morte, somente com essa cessa a sua personalidade.

O Direito brasileiro não reconhece qualquer possibilidade de perda da personalidade em vida. Somente com a morte a personalidade jurídica é extinta, não significando a abolição dela a cassação de direitos políticos, prevista na Constituição Federal de 1988, art.15.

A ciência moderna defende que a vida do indivíduo está subordinada à atividade cerebral. Uma vez constatada a morte encefálica do indivíduo se finda à vida, logo, a personalidade.

\section{CONCLUSÃo}

Mediante ao exposto, analisamos os requisitos da personalidade no Direito Romano e no Direito Brasileiro. É visível que este buscou seus fundamentos, alicerce, no Direito Romano. Logo, verifica-se que não se pode compreender por completo o mundo jurídico atual se não buscarmos suas raízes, origens, calcadas no Direito Romano. 


\section{Bibliografia}

ALVES, José Carlos Moreira. Direito Romano. $13^{\mathrm{a}}$ ed., vol I, Rio de Janeiro. Forense, 2002.

AMARAL, Francisco. Direito Civil - Introdução. $3^{\text {a }}$ ed., Rio de Janeiro. Renovar, 2000.

BEVILÁQUA, Clóvis. Teoria Geral do Direito Civil, 1980.

BITTAR, Carlos Alberto. Curso de Direito Civil. Vol.1. São Paulo. Forense Universitária, 1994.

HENRI DE PAGE. Traité Elementaire de Droit Civil Relge. Bruxelas, 1948

GAGLIANO, Pablo Stolze. Novo Curso de Direito Civil. Vol. I. $5^{\text {a }}$ ed., São Paulo. Saraiva, 2004.

GOMES, Orlando. Introdução ao Direito Civil. 18a ed., São Paulo. Forense, 2002.

GONÇALVES, Carlos Roberto. Direito Civil Brasileiro. Vol I. São Paulo. Saraiva, 2003.

WALD, Arnold. Curso de Direito Civil Brasileiro, Introdução e Parte Geral. $8^{a}$ ed., São Paulo. Revista dos Tribunais, 1995.

PEREIRA, Caio Mário da Silva. Instituições de Direito Civil. Vol. I, $20^{\mathrm{a}}$ ed., Rio de Janeiro. Forense, 2004.

RODRIGUES, Silvio. Direito Civil. Vol. I. 32ª ed., São Paulo. Saraiva, 2002.

SEMIÃO, Sérgio Abdalla. Os Direitos do Nascituro - Aspectos Cíveis, Criminais e do Biodireito. Belo Horizonte. Del Rey, 1998.

PINTO, Agerson Tabosa. Direito Romano. Fortaleza, Imprensa Universitária, 1999.

TEPEDINO, Gustavo. Temas de Direito Civil. Rio de Janeiro. Renovar, 1999. 